\title{
Conceptualising and building trust to enhance engagement, achievement and feedback-seeking behavior of under- served students: exploring instructor antecedents in online tertiary education
}

\author{
Ameena Payne, Cathy Stone ${ }^{1}$, Rebecca Bennett ${ }^{2}$ \\ 1 University of Newcastle \\ 2 Murdoch University
}

Funding: The author(s) received no specific funding for this work.

Potential competing interests: The author(s) declared that no potential competing interests exist.

\section{Abstract}

Online educators must establish the kinds of trust that are uncommon in didactic, mechanical pedagogies. This conceptual paper asserts the importance of building and sustaining trust between higher education students and their instructors within the online environment. Instilling trust can construct sustainable learning environments that are abundant with collaborative inquiry and dialogue. The themes explored in this paper highlight and investigate the conceptual construct of trust and its antecedents.

We address the nature and purpose of interpersonal trust in student/instructor relationships within online higher education institutions. We also explore several factors (in particular, performativity, casualisation of teaching staff, neoliberalism, non-traditional student identities and the digital divide) which influence the development of trust. We investigate the role of trust in influencing student feedback-seeking behaviour, engagement and achievement, in terms of attainment of academic goals. Notably, we highlight the importance of further inquiry into methods of rapport-building in higher education. Theoretical foundations have been drawn from Indigenous scholarship as well as organisational and socio-psychological literature. We close by welcoming further discussion of and reflection on institutional practices and performance measures in the digital environment and whether they allow instructors to embed relational aspects and elicit cognitive and affective trust from their students.

\section{Implications for practice}

- As higher education (HE) shift to online, decision-makers must acknowledge the importance of relationship-building between under-served students and instructors

- HE institutions (HEls) must recognise the nature of this online cohort through more tailored approaches that consider both the needs and the strengths of this diverse group of students 
- HEls must consider the rise of measurement culture and the impacts on "good teaching" and professionalism

- Trust and feedback-seeking behaviour are areas full of research potential.

\section{Introduction}

Exploration of the construct of trust assumes that trust between students and their instructors is not automatic due to variations in identity and differences in perceived power (Sybing, 2019). Yet, a study of 245 undergraduate students found a statistically significant relationship between student-instructor trust and course performance (Cavanagh et al., 2018). "Students who reported high levels of trust in their instructor tended to achieve higher course grades than those with lower trust levels" (Cavanagh et al., 2018, p. 5). As higher education (HE) becomes increasingly more accessible and diverse, the need for more dynamic forms of teaching and relationship-building is ever more vital. "Students at the margins are not served by the status quo in higher education" (Sybing, 2019, p. 19). As we contemplate the intricacies of what we will be referring to as under-served students' positions in $21^{\text {st }}$ century education, the aim is to encourage "practitioners, and researchers to explore, investigate, describe, and interrogate our own assumptions and thinking as well as our own practices and positions" (Nakata et al., 2004, p. 1). It is important for instructors and HE institutions (HEls) to adapt to the growing identities that student diversity is bringing. Such an approach involves moving beyond student evaluations, attrition and completion rates. That is not to say that there is not a place for them. However, it means understanding the importance of building relationships that ensure deepened learning and widened participation of equity students for professional practice in a range of contexts (Nakate et al., 2004).

Between 2008 and 2017, Australian HEls saw much growth in equity groups within domestic undergraduate enrolments. There was an 123\% increase in students with disability; 105\% increase in Indigenous students; $66 \%$ increase in students from low socio-economic backgrounds; and 50\% increase in regional and remote students (Universities Australia, 2020). Eurocentric, outsider-based epistemologies have been utilised to develop and implement practices within online HE often inflating the inequalities which it is often said they would address (Thuing \& Pearson, 2019). Prior ideas in education assumed that we have a homogeneous student population and that there were no issues around building rapport (Mordal Moen et al., 2020; Noddings, 2013). "The increase in innovative technology [...] and how knowledge is accessed, shared, and legitimised in Australia is beginning to change" (Thuing \& Pearson, 2019). Recent geopolitical movements, driven in part by social media (Thuing \& Pearson, 2019), are prompting an uprising in education that more deliberately considers inequality, diversity, widening participation and varied educational needs (Payne, 2021b).

According to the Quality Indicators for Learning and Teaching (QILT) in Australia, undergraduate enrolment diversity across all years of study is not matching diversity at commencement. Aboriginal and Torres Strait Islander (First Nations/Indigenous) students, mature age, low socio-economic status (SES) and those with reported disability are amongst the students who most commonly consider early departure. Similarly, these equity groups demonstrate the lowest positive ratings of satisfaction and engagement within their undergraduate courses (The Social Research Centre, 2021). However, to redirect attention from a deficit narrative in students, their cultures and backgrounds, to critical reflection 
on education practices, this paper adopts the term under-served students. In addition to the aforementioned equity groups, we include regional/remote and first-in-family students. The term under-served is a deliberate choice as it identifies individuals "not through their personal characteristics but through their relationship with schooling and allows recognition that marginalisation is a product of the institutions and systems we create and sustain" (Te Riele, 2004, p. 3).

\section{Performativity and 'good teaching'}

The rise of measurement culture

Neoliberalism has increased competition and corporate ethos within universities. The neoliberal agenda and privatisation of higher education across the globe has seen universities increasingly adopting models for assessing quality, output and efficiency from corporate culture (Arthur, 2009; Biesta, 2010; Holloway \& Brass, 2018; Schmidt, 2021). This agenda requires academics to perform in response to systems of increased casualisation and surveillance rooted not in virtuous notions of academic service but "institutional self-interest" (Ball, 2003, p. 218). Central to this ethos of measurement is performativity - "a culture in which means become ends in themselves so that targets and indicators of quality become mistaken for quality itself" (Biesta, 2010, p. 13). Performativity is a technology that links business-derived concepts of measurement, comparison and evaluation to effort, values, purposes and self-understanding (Ball, 2003; Holloway \& Brass, 2016; Schmidt, 2019). "A basic tension exists between higher education's idealised niche as a public good and its instrumental, exchange value" (Hill and Lawton, 2018, p. 602). "Higher education is increasingly being located within the demands of economic productivity" (Singh, 2001, p. 8).

These metrics are determined by institutions (Smith, 2017), not by students - even though they often include "student feedback" measures that evaluate pre-determined aspects of teaching. "Universities place great emphasis upon having positive feedback scores" (Flodén, 2017, p. 1055) as means of judging the performance of both lecturers and universities" (Arthur, 2009, p. 441). Sessional academic staff are conscious of the punitive outcomes that come with audit culture (Smith, 2017). "Student evaluations lie at the interface between professionalism and performativity" (Arthur, 2009, p. 442). It is worthwhile to note that there are key aspects of student evaluations which literature challenges (Arthur, 2009; Flodén, 2017). For example, personality attributes such as "enthusiasm, charisma, humour, kindness and a genuine interest in students' progress" (Grayling, 2015, p. 1) rarely feature in feedback measures. Instead, evaluations of learner experiences tend to focus on cognitive mechanisms, such as clarity and efficacy of knowledge dissemination, as opposed to affective elements, such as inspiration, inclusion, safety and trust. This is despite empirical research which indicates that student perceptions of "good" teaching, emphasise attention, affection and appreciation as determinants of teacher quality (Raufelder et al, 2016).

The 'terrors of performativity' 
Performativity is the attempt to measure and track elements of academic work and teaching that many argue are not quantifiable (Ball, 2003; Biesta, 2010; Schmidt, 2019). Through its employment of judgements, comparisons and displays, performativity is a mode of regulation and measure of outputs. Aspects of teacher professionalism are influenced by data driven accountability policy regimes, not only in Australia, but across the globe (Arthur, 2009). Such influence is argued to be increasing rather than reducing educational inequalities and hindering teacher professionalism by shifting "academics as professionals to academics as proletarians (Arthur, 2009, p. 442). "This transformation has been used as much to denote the repositioning of higher education to serve more efficiently as the handmaiden of the economy as to signify the drive to align higher education with the democracy and social justice agenda" (Singh, 2001, p. 7). Ball (2003) draws attention to the differing agendas: "Are we doing this because it is important, because we believe in it, because it is worthwhile? Or is it being done ultimately because it will be measured or compared?" (p. 220). This shift has rearticulated the notion of public universities from a "public good" geared towards producing an educated citizenry to a conception of higher education as an individual economic investment” (Kimber and Ehrich 2015 as cited in Keddie et al., 2020, p. 98). Thus, a "good teacher" is measured by efficiency, student results and limited feedback mechanisms, as opposed to concepts such as student growth, liberation or emancipation.

\section{A two-way street}

Student perceptions of what makes a "good teacher" at university, are often at odds with the neoliberal agenda of higher education. Where qualitative student feedback suggests that institutions which are increasingly focused on positivist approaches to tracking and measuring teaching "quality" using metrics, which can be "measured" and ranked. "Care and collegiality are being superseded by individuation and competitiveness" (Smith, 2017, p. 598). To build trust we need to look after both sides of the relationship: the difficulties that a lecturer's contract status produces in terms of the quality of their teaching and relationships with students (Hitch et al., 2017). Key pedagogical difficulties brought up by participants concerned a lack of ability to build longer-term knowledge of/relationship with the students they taught; a lack of involvement in planning or constructing courses on which they taught, compounded by the emotional labour of attempting to hide such difficulties from students (Read \& Leathwood, 2020). Teaching is a caring profession (Te Riele, 2004). "Great teaching requires a co-creation of knowledge between great teachers and engaged students" (Hill \& Lawton, 2018, p. 604). "If one were to analyse what goes into being an inspiring teacher in this sense, the list would include enthusiasm, charisma, a capacity to clarify and make sense, humour, kindness, and a genuine interest in students' progress" (Grayling, 2015).

\section{Centring under-served students}

\section{Equity student groups}

Online learning plays an increasingly important role in the participation of historically underrepresented students in higher 
education (HE) - those whom we argue are under-served by their institutions. The opportunity for greater flexibility offered by online learning allows for higher education to "meet students where they are currently placed, allowing participation in ways that suit the student considering their individual circumstances and the personal barriers they may have" (Dodo-Balu, 2018, p. 35). Students from the Australian Government-identified higher education equity categories (DESE, 2019), of low socio-economic background, regional and remote students, Aboriginal and Torres Strait Islander (First Nations People) students, and students with disability (Cardak et al., 2017; Halsey, 2017; Kent, 2015; Pollard, 2018; Stone, 2017) are enrolling in $\mathrm{HE}$ distance/online mode at higher proportional rates than in the more traditional on-campus mode; also those who are first in their families to enter university (Stone, O'Shea, May, Delahunty, \& Partington, 2016). Literature also suggests that non-Indigenous academics experience discomfort in teaching Indigenous students (Bullen et al., 2021; Day et al., 2014). It has been concluded that "the focus curriculum and content has not been matched by developing [nonIndigenous] academics' capability in curriculum delivery... [which] is likely to negatively impact on Indigenous student retention" (Bullen et al., 2021, p. 7). This is a detriment to equity students, particularly First Nations students who must engage with and navigate Western knowledge and meaning making (Nakate et al., 2004; Day et. al., 2014).

Most online students are also enrolling later in life and as part-time students, rather than as full-time school-leavers. They tend to be juggling multiple demands on their time, energy and finances, including family responsibilities and employment (Bissonette, 2017; Chawinga \& Andrew, 2016; Hewson, 2018; Ilgaz \& Gülbahar, 2015; Knightly, 2007; Moore \& Greenland, 2017; Park \& Choi, 2009; Signor \& Moore, 2014; Stone \& O’Shea, 2019a), with women more strongly represented amongst this cohort (DESE, 2019). These demographic characteristics apply to both undergraduate (UG) and postgraduate (PG) online students, with DESE (2019) figures demonstrating that $70 \%$ (UG) and 82\% (PG) of the online cohort are aged 30 and over, with women (68\% UG; 64\% PG) and part-time students (52\% UG; 70\% PG) in the majority.

Women are particularly disadvantaged in higher education by their traditional gendered role of carer within the family (Chesters \& Watson, 2014; Mallman \& Lee, 2014; Pocock, Skinner \& Ichii, 2009; Stone \& O'Shea, 2012, 2013), with women accounting for $70 \%$ of primary unpaid carers of children (Australian Human Rights Commission, 2018) and spending $110 \%$ more time on caring for dependent children than their male partners (Wilkins \& Lass, 2018). It can therefore be argued that gender equity is being enhanced through the "the flexibility that online study promises...to manage study around other family commitments" (Stone \& O'Shea, 2019b, p. 98).

\section{Developing an understanding and appreciation}

Many have argued that $\mathrm{HE}$ institutions (HEls) must acknowledge the nature of equity students through a more tailored and targeted approach that considers both the needs and the strengths of this diverse group (Devlin \& McKay, 2018; DodoBalu, 2018; Kelly, Coates, \& Naylor, 2016; Lewis, 2017; Salmon, 2014; Stone, 2019). HEls need to recognise the busy, complex lives of these students and the impact this has on student "identity". For the full-time, on-campus, school-leaver student, it may be expected that student identity is likely to be central to their lives and hence prioritised. However, for online students with multiple pressures and responsibilities, student identity will inevitably take a back seat when it 
conflicts with other non-negotiable identities such as parent, paid worker and/or family carer (Hewson, 2018; Ragusa \& Crampton, 2018; Nakata et al., 2004; Stone et al., 2019).

The lower retention and completion rates that are reported amongst the online student cohort (DESE, 2019; Greenland \& Moore, 2014, Stone, 2017) may be much more connected with the lack of understanding and appreciation of the nature of this cohort than with the online mode of delivery. Retention of distance, online students has been estimated to be at least $20 \%$ poorer than for on-campus students, with 40\% fewer completing their degrees over a nine-year period (DESE, 2017a) and withdrawal without a qualification being 2.5 times more likely (DESE, 2017b). However, it has been argued that, only through "recognising, understanding and valuing this cohort" (Stone \& O'Shea, 2019a, p. 66) can an equitable experience be achieved (Day et al., 2014). Whilst ever institutions expect this cohort to be largely the same as that on-campus, there are likely to be "gaps between expectations and delivery" (Hewson, 2018, p. 10). Hewson (2018) stresses that "a dominant [sic] student identity... is not realistic for online students" (p. 11) as they "cannot prioritise their student identity over their work identity" (p. 10). Other researchers mention the "important fundamental differences between on-campus and online learners" (Moore \& Greenland, 2017, p. 57) as well as the "subculture expectations and rules" within universities that may not always be "clear to online students" (Devlin \& McKay, 2018, p. 161).

Tailoring the design of courses, the teaching, learning and support more effectively with equity students in mind (in other words, ensuring they are more appropriately served) is therefore essential. Incorporating the Reciprocal Research Partnership Model and Cultural Interface Theory (CIT) conceptualises "the space in between Western and Indigenous ways of knowing and being" (Uink et al., 2021, p. 181). These ways of being and knowing could be lived experience of the world, it may mean traditional understanding which has been passed down or it may mean local or historical knowledge all of which are not well-represented in course content (Nakata et al., 2004). Research into ways of doing this is extensive, including the importance of meaningful and effective communication (Bullen et al, 2021), contact with instructors and other students (Lambrinidis, 2014), the "presence", "accessibility" and "responsiveness" of the online teacher (Vincenzes \& Drew, 2017, p. 13), to avoid online students experiencing a sense of isolation and "aloneness" (Resop-Reilly, GallagherLepak, \& Killion, 2012, p. 104) as well as the importance of effective online course design and delivery (Devlin \& McKay, 2016; Dreamson et al., 2016; Thuing \& Pearson, 2019). "Positive learner-centred relationships founded on respect, trust, empathy and warmth are acknowledged as important to education and learning" (Bullen et al., 2021, p. 21). Within the curriculum, laying the foundations for trust to be built facilitates student uptake of new information and concepts (Simper et al., 2021). Academia will begin to know it is on the right path when under-served students are able to see themselves and their story reflected within the course (Mukandi \& Bond, 2019).

\section{Bridging the digital divide}

Further support for increased focus on the significance of trust in the teacher-student relationship lies in potential layers of digital inequity and absence of choice in learning modality for online students. Research into the digital divide between 
and within nations has found that digital inequity intersects with inequities in gender, race, social class, geography and culture (Van Dijk, 2005, Gunkel, 2003; Dimaggio \& Hargittai, 2001). Referred to as the 'iron triangle" of access, cost, and quality" (Hill \& Lawton, 2018, p. 604), digital inequality is a result of complex and intersecting social, financial and geographical constraints - depending on where someone lives (e.g., rural or remote vs urban contexts), financial stability, digital literacy and the quality and quantity of hardware through which online learning might be accessed. Thus, "those in more privileged positions generally have more autonomy, support, and skill, and they benefit from the Internet in ways that those lower in the hierarchy do not" (Dobransky \& Hargittai, 2016, p.19). Rurality, for example, can be as prohibitive to full and equitable online participation as race and class (Crawford, 2021; Stern et al., 2009). Even in developed nations, such as Australia, students in rural and remote areas experience issues of poor connectivity, limited internet quotas and high internet costs (Crawford, 2021; Stone \& Davis, 2020). These issues extend into urban contexts, where research has found that 1 in 5 Australian households access the internet only through mobile-phone technology (Thomas et al., 2017) and in the case of Indigenous Australians, this figure rises to $49 \%$ of the population (Bennett et al, 2020; Thomas et al., 2017). Mobile internet access is inequitable because it is more expensive than fixed line in the long term. However, fixed-line internet can be prohibitive to low SES demographics, due to high set-up fees and contractual monthly repayments which require a stable and predictable income and long-term residence.

Internet access and cost are not the only factors that might impact the online university student experience, with other issues including: available time and spaces for online study; proximity and accessibility of technological support; and digital literacy. Confidence and experience (Hargittai \& Hsieh, 2013) also influence the ease with which online study is conducted. Older and cheaper technology, patchy internet infrastructure and time and space constraints on study time can lead to struggles and compromises, such as not being able to participate in synchronous time tutorial discussions, missing or broken camera or microphone functions, having to study at the local library or late at night to ensure access to a computer and the internet. For on-campus students, digital inequities are ameliorated in the provision of high-quality technological hardware and stable, high speed broadband internet which can easily process multimedia content, live group video discussions, assessment preparation and submission and so on. However, issues of digital underservice arise in the assumption that online university students have equivalent access, cost and quality of digital infrastructure, compared to one another and to on-campus cohorts. When an online student's technology is unstable and untrustworthy, the role of the tutor becomes increasingly salient, as the value of online learning relies on a combination of product quality and the overall educational experience (Howard et al, 2019). Thus, for students who experience a lower quality educational product, due to the technological limitations that studying remotely can bring, "teaching presence is essential to balance cognitive and social presence" (Howard et al., 2019, p.). To ensure educational equity, it is important that tutors of digitally under-served online students not only act as mediators between the content and the learning, but as stewards through Learning Management Software and digital communities of practice that contextualise their learning (Jones \& Bennett, 2015). The development of meaningful and trusting relationships between teacher and student might provide insight into the online learner's positioning within the digital hierarchy enabling them to build a reliable "bridge" over digital divide. 
Another consideration when teaching online student cohorts is the awareness that many who study online do so because their life circumstances mean that studying on a physical campus is simply not possible (Stone et al., 2019). Such students do not choose online study; they choose to study, and online is the only option. This means that educators cannot make presumptions about online students' familiarity, confidence and literacy in terms of online learning, nor can they assume that students are learning online because this is their preference. Having said that, the tenacity and resilience of underserved students has been well documented (Bennett, et al., 2021; Uink et al., 2021; Shield, 2009; Stone, 2019) and, with effective teaching and mentorship, students can work through digital literacy and access issues to have a successful and rewarding study experience online. This was exemplified in Indigenous student responses to the rapid transition to online learning in a university semester due to Covid-19 pandemic restrictions, such as typing up major essays on iPads and completing studies whilst caring for multiple children at home (Bennett et al., 2020). In one university Aboriginal Education Unit, a relationships-first strategy meant that retention rates were consistent before, during and after Covid-19 campus shutdowns. This approach, which included daily phone calls, weekly emails and support staff acting as mediators between tutors and students who were waiting for internet access or computer facilities to arrive in their homes intentionally focused on supporting student wellbeing, as opposed to pass rates and grades (Bennett et al, 2020). Examples such as this demonstrate that digital inequity is not prohibitive, when students trust their teachers and institutions to work with them to resolve extra-curricular, and curricular, issues that can impact the efficacy of the online learning experience.

\section{Conceptualising trust}

We suggest HE institutions (HEls) enable practitioners draw upon relational factors to enable under-served students to persist in online HE contexts. Pedagogic gaps and deficiencies are highlighted in digital learning environments (Dron et al., 2004). Conceptualising trust will "assist universities to become more inclusive environments for all students and to intentionally foster empowering educational experiences" (Uink et al., 2021, p. 179).

Using a few related constructs, we base the definition of trust as proposed by Tschannen-Moran (2004; as cited in Carless, 2013): "[students'] willingness to be vulnerable to [their instructor] based on the investment of faith that [their instructor] is open, reliable, honest, benevolent and competent" (p. 91) "to take appropriate steps that benefit [the student] and help [them] achieve his learning and career objectives" (Ghosh et a., 2001, p. 325). Mayer and colleagues (1995) include "irrespective of the ability to monitor or control that other party" (p. 712) signaling an asymmetrical power dynamic at play within the relationships of instructors and students. "Trust in a dyadic relationship arises from attributes associated with a trustee and a trustor" (Jarvenpaa, et al., 1998, p. 31).

The trustor's propensity to trust is a trait that conveys a generic expectation of how trusting one should be; it is influenced by a trustor's cultural, social, developmental experiences and personality type (Gwebe et al., 2007; Jarvenpaa et al., 1998). Trust encompasses moral, cognitive, and emotional elements (Jones \& George, 1998). "In terms of trustor versus trustee attributes, prior research has found that the trustee attributes explain more of the variance in interpersonal trust than does 
the trustor's general propensity to trust" (Jarvenpaa et al., 1998, p. 31).

We focus on two categories of trust: (1) cognitive-based trust which is grounded in students' belief in their instructors' dependability and reliability, and (2) affective-based trust, grounded in students' perceptions and experiences of their instructors' interpersonal care and concern (McAllister, 1995). "Generally, researchers agree that cognition- and affectbased trust have contrasting features" (Choi et al., 2014, p. 606). For instance, cognition-based trust is formed by the expectation that the other is credible in others' knowledge, skill, and competence to perform a task (Choi et al., 2014); whereas affect-based trust consists of an emotional bond based on mutual respect, genuine care, and concern for another"s needs (Choi et al., 2014; Zhou et al., 2020). Cognition- and affect-based trust are expected to have different influences on feedback-seeking behaviour (FSB) and on students' perceptions of the value of feedback (Choi et al., 2014).

Both affect-based and cognition-based trust are influential (Choi et al., 2014). Therefore, initial interactions serve to establish trust; each instructor-student interaction thereafter poses as an opportunity for trust to be either reinforced or reduced. Linked to the task-based side of work, cognitive trust in a student-instructor relationship may be built through the timely response to student queries. Affective trust is often underpinned by security and based on relational aspects such as social presence (Rourke et al., 2001) and teaching presence (Stone \& Springer, 2019).

Conceptions of studentinstructor relationships have been required to shift from "the mechanistic to the responsive" (Boud \& Molloy, 2013, p. 703). Deepening student-instructor relationships through trust may impact on student engagement with the learning process (Carless, 2013). "The college teacher may not always be expected to connect with their students on an emotional, casual basis, or engage and validate the knowledge that they bring to the classroom" (Sybing, 2019, p. 18). With increased instructor workloads and the uncertainties caused by the challenging circumstances of 2020 , time for the development of interpersonal relationships may have been limited. Yet, it is imperative that HEls recognise that lack of trust may signal decreased student engagement and active learning, particularly for under-served students (Bullen et al., 2021). Past "scholars have widely acknowledged that trust can lead to cooperative behavior among individuals, groups, and organizations" (Jones \& George, 1998, p. 531). Despite the strategic consequences of student trust on student outcomes and experiences, relatively little attention has been focused on trust within online higher education or understanding its antecedents thoroughly (Ghosh et al., 2001; Carless, 2013). Only recently has research begun to explore the importance of establishing rapport between teachers and students in HE contexts (Arghode et al., 2017; Canty et al., 2020; Carless, 2013; Crawford \& Johns, 2018; Lee, 2015; Redmond et al., 2018; Stone \& Springer, 2019).

"Contemporary education, particularly higher education, has begun to shift away from teacher-dominated relationships to the role of teacher as facilitator, or "affiliation (support) dominated relationships" (London, 1995 as cited in Payne, 2021c, p. 9). "Of course, even if insisting on taking an affiliate relationship, instructors are still marking the students' performance" (Payne, 2021c, p. 11). "This means that there are parts of the teacher"s authority that cannot be overlooked" (Jonsson, 2012 as cited in Payne, 2021c, p. 12). Chickering and Gamson (1987) provided some early definition to pedagogies that transcended simple knowledge transfer to establish rapport that is built on empathy, respect and trust (Sybing, 2019). In 
their article about undergraduate teaching, Chickering and Gamson (1987) emphasised several aspects of a high impact instructor which include:

1. Developing reciprocity and cooperation;

2. Communicating high expectations; and

3. Respecting diverse talents and ways of learning.

Trust can therefore be explained as a relational practice that enables growth, recognition, empowerment, community and possibility. Trust is vital in both team and dyadic relationships. "Trust has been linked to factors such as commitment, cooperation [and] positive evaluation of effectiveness" (Ghosh et al., 2001, p. 324). "It is pivotal in preventing geographical distance from leading to psychological distance" (Jarvenpaa et al., 1998, p. 30). Trust is even more essential in the disembodied, digital learning environment.

\section{Antecedents of trust}

The year 2020 marked an abrupt migration of higher education institutions (HEIs) shifting online in response to global events. Yet, rapid uptake to online commonly maintained mechanical, impersonal, didactic learning environments which have not served all students equitably. According to students, a critical issue in the uptake to online higher education has been a lack of adequate support, interaction and engagement with academic staff (Martin, 2020).

Given the already steady growth in fully online higher education supplemented by the rapid increase in online educational delivery due to Covid-19, it is even more vital to re-evaluate teaching pedagogies that are not adequate in fostering community, effective communication and, ultimately, enhancing the digital learning environment. Like Jones and Bennett (2014), we also "argue for a greater emphasis on conceptual investigations into how teaching and learning might be repositioned in a digitally networked age" (p. 194). We suggest an approach for HEls to enable educators to build trust in actions and interactions within the online learning environment. Respect and empathy reinforce trust (Carless, 2013). Our approach is based on the Reciprocal Research Partnership Model (RRPM) which seeks to enable instructors to actively acknowledge the varied experiences and contributions that learners bring by incorporating "the Indigenous worldviews of respect, relationships, responsibility, and reciprocity" (Uink et al., 2021, p 180).

We discuss five (5) trustee, or instructor, attributes which were identified based on a review of literature in many disciplines (Ghosh et al., 2001; Gwebu et al., 2007; Jarvenpaa et al., 1998; Joughin et. al., 2020): competence, openness, congeniality, sincerity and integrity.

\section{Competence}

Expertise is defined as perceived mastery and competence within one's field(s) (Ghosh et al., 2001). Students with 
cognition-based trust in their instructors are likely to believe in their instructors' task-related skill sets (Choi et al., 2014). Yet, 'the tension between expressing vulnerability and seeking credibility creates challenges for learning and teaching' Molloy \& Bearman, 2018, p. 1). However, this 'perceived [vulnerability] on the instructor's part can provide useful opportunity to validate students' knowledge and mitigate differences in power' (Sybing, 2019, p. 31). This is described as 'intellectual candour' (Molloy \& Bearman, 2018).

\section{Openness}

Under-served students are engaging in higher education with an array of aptitudes, knowledge, opinions and values; their backgrounds affect how they engage with and construe information (Payne, 2021b). Further, the embedded nature of emotion in learning, follow[s] the principle that learning, by definition, demands some form of risk taking, or openness, on the part of the instructor, and being open to the possibility that things can be done or thought about differently (Molloy \& Bearman, 2018; Uink et al., 2021). When students' perspectives are acknowledged and encouraged, risk-taking is made possible (Carless, 2013).

\section{Congeniality}

The ability of an instructor to create a supportive and friendly environment lays the foundation for increased engagement (Arghode, 2017). Researchers have argued that students being on a first-name basis with their instructors can reduce power imbalances (Sybing, 2019; Xu \& Carless, 2017) and assist instructors with 'mitigating [their] role as authority figure' (Sybing, 2019, p. 30). Further, awareness of equity students' contexts and social-affective emotions fosters a culture of that nurtures shared interest, support and cooperation (Bullen et al., 2021; Sybing, 2019; Uink et al., 2021; Xu \& Carless, 2017).

\section{Sincerity}

Successful, inclusive and culturally responsive teaching relies on acknowledging the relational dimensions (Bullen et al., 2021; Te Riele, 2004). When students sense sincerity, or "'truth-telling" [they] extend trust in order to lessen the vulnerability and uncertainty associated with the relationship' (Ghosh et a, 2001, p. 328). Sincerity can be thought of as HEls' and educators' assurances to fulfilling commitments to honesty and integrity (Ghosh et al., 2001).

Integrity

Integrity of the educator and HEl are significant determinates of student/instructor trust (Ghosh et al., 2001). Refusal to sacrifice ethical standards for organisational or individual benefit can be viewed as integrity (Ghosh et al., 2001). Trust requires interaction. 'It is vital to be responsive and adaptable to students' (Payne, 2021a, p. 8). For the instructor, demonstrating high availability and presence and following through with expected or promised action creates opportunities 
for further interaction (Arghode et al., 2017).

Virtual spaces can be perceived as 'cold \& impersonal' (Jarvenpaa, Knoll, Leidner, 1998, p. 32). Building competence, openness, congeniality, sincerity and integrity can increase confidence and security within instructor-student relationships and 'promote substantive and influential information exchange' (Jarvenpaa et al., 1998, p. 30). Qualities of high trust spaces include optimism \& excitement; good time management (e.g., communicating deadlines); clear, mutual goals (Joughin et al., 2020; Leenknecht et al., 2019); proactive action; continuous streams of communication; and prompt, detailed responses (Jarvenpaa et al. 1998; Arghode et al. 2017). Instructors can build student trust by cultivating a sense that, while active learning and engagement may involve more work, they have students' best interests in mind, they have their back and that they are in this together; it is important to move beyond performative allyship and to support these declarations through actions (Bullen et al., 2021; Cavanagh et al., 2018). 'Psychological empowerment is positively associated with feedback-seeking behaviour' (Huang, 2012, p. E103).

In the study conducted by Arghode and colleagues (2017), 'participants unanimously agreed that respecting students' values and creating an atmosphere in class that breeds trust, support, and healthy interaction is valuable to improve student learning' (p. 141). It was acknowledged that a supportive and safe atmosphere promotes participation (Arghode et al., 2017). Such an environment 'helps professors learn more about students' strengths and weaknesses' (Arghode et al., 2017 p. 141). As the following section discusses, trust has also been linked to increased feedback seeking behaviour [FSB] (Choi et al., 2014).

\section{Feedback-seeking behaviour (FSB)}

Feedback-seeking behaviour, in the context of higher education, can be viewed as students' 'proactive search for feedback information' (Crommelink \& Anseel, 2013, p. 233). 'Feedback is one of the most widely used psychological interventions to stimulate learning and development' (Crommelinck \& Anseel, 2013, p. 233). Students' feedback-seeking, response to and uptake of feedback is influenced by their socio-affective perceptions of their instructor (Carless, 2013), psychological empowerment (Huang, 2012; Martin, 2006) and goal orientation (Huang, 2012; Joughin et al., 2020; Leenknecht et al., 2019; Martin, 2006). 'It takes trust to open up the learning environment to student initiative' (Carless, 2013, p. 92). Organisational and social psychology research suggests that students may not wait around passively for their instructors to initiative 'learning conversations' (Gould \& Day, 2013); instead, they may (and are encouraged to) seek it proactively (Crommelink \& Anseel, 2013). Pre-emptive feedback-seeking can enable students to gain important performance information which can be used to adjust their work and behaviour, leading to deepened levels of learning, creativity, community and increased performance and satisfaction (Crommelinck \& Anseel, 2013; Huang, 2012). Research has reasoned that those who habitually sought and received feedback demonstrated higher goal attainment and deepened learning compared with individuals who sought feedback less often. 
Research indicated that students are intentional regarding the method by which they seek feedback and from whom they seek it (Crommelink \& Anseel, 2013). Impersonal digital spaces may discourage feedback-seeking behaviour. It has also been argued that domineering, inflexible and unapproachable instructors are far less likely to be trusted by students (Carless, 2013); such instructors become 'a source of distrust and defensiveness' (Carless, 2013, p. 93). Instructors who demonstrate the five antecedents of trust will be more likely to be reliable sources of feedback. The challenge, then, is to begin in a way that develops a culture of trust (Gwebu et al., 2007), through collegiality, openness and contribution and then using presence to maintain the best possible levels of engagement (Payne, 2021a).

We argue that there is strong evidence that cognitive and affect- based trust have positive effects on student engagement, performance (Cavanagh et al., 2018), satisfaction and feedback-seeking frequency and uptake. 'This type of supportive climate creates a "comfort zone" where students are willing to ask for assistance and professors feel safe to set high expectations' (Arghode et al. 2017, p. 129).

\section{Conclusion}

This paper contributes to the ongoing transformative agenda of online higher education. "Indigenous knowledge also reminds us that in everyday practice, Indigenous people are often working in accordance with other systems, values and practices passed down while at the same time making sense of and operating in Western frameworks" (Nakata et a., 2004, p. 1). Yet, it serves to shift attention from the prevailing language of deficit narratives in relation to the education of traditionally under-served students, towards a strengths-based, reciprocal partnership model that embeds and honours Indigenous ways of knowing and being (Martin, 2006; Uink et al. 2021). We also aim to expand upon Bulleen and colleagues' (2021) literature on "educator discomfort" by "moving toward deeper exploration of the experiential, psychological, and contextual factors" associated with educators' engagement with Indigenous students in 'mainstream' learning environments" (p. 1).

HEls seeking to not only survive but also to innovate in the increasingly competitive environment can use this article's assertions and findings to design effective strategies to build and maintain trust. The datafied teacher faces increased pressures to rely on numerical data to guide their pedagogical decisions and classroom practices. In these data environments, the "quality" of the teacher is narrowly defined by numbers, while "improvement" is defined as increasing these numbers, rather than improving practice" (Holloway, 2020, p. 4). Acknowledging the "fraught transactional nature of 'ticking the box' with regards to staff personal development opportunities" (Bullen et al., 2021, p. 23), we recommend that HEls facilitate meaningful chances for staff to build transformative approaches to instructor-student interactions that reinforce confidence (Martin, 2006) - "engaging from the position of an ally" (Bullen et al., 2021, p. 22).

We view the construct of trust and feedback-seeking behaviour within higher education as an area full of research potential. "Student equity is - now more than ever - everyone's responsibility" (Bullen et al., 2021, p. 2). Flowing onward 
from the work of Joughin and colleagues (2020), we believe further empirical knowledge and discourse is needed to shed light on this neglected aspect of academic practice support for equity students entering tertiary study is crucial if we are to mount a concerted effort to close the gaps (Nakata et al., 2004). Like Molloy and Bearman (2018), we believe practitioners "should embrace the ongoing struggle between expressing vulnerability and seeking credibility" (p. 9). Students' trust in their instructors plays a key role in psychological empowerment and accomplishment (Huang, 2012).

An informal teaching approach, the use of personal storytelling and humour, teaching presence and a collaborative process in knowledge construction are viewed as critical in efforts for developing an environment where under-served students can feel more secure (Bullen et al., 2021; Grayling, 2015; Payne, 2021a; Stone \& Springer, 2019). Only when HEls and educators build, demonstrate and sustain genuine trustworthiness and care can education act as the great social equaliser (Payne, 2021b). It may also be worthwhile to investigate in greater detail how to develop each specific type of trust in digital learning environments. We aim to continue the conversations and opportunities that re-imagine relationships at the nexus between equity students and the construction of transformational, digital learning environments that are rich with deepened learning, openness, congeniality, sincerity and integrity.

\section{Acknowledgement}

We would like to extend our sincere thanks to Dr. Bep Uink (Kulbardi Aboriginal Centre, Murdoch University). We acknowledge the Traditional Owners of Country and pay our respects to Elders past and present.

\section{References}

- Arghode, V., Wang, J., \& Lathan, A. (2017). Exploring Instructors' Practices in Student Engagement: A Collective Case Study. Journal of the Scholarship of Teaching and Learning, 17(4), 126-149. https://doi.org/10.14434/v17i4.22099

- Australian Human Rights Commission. (2018). Face the facts: Gender equality 2018. Canberra, Australia: Retrieved from https:/www.humanrights.gov.au/education/face-facts/face-facts-gender-equality-2018

- Arthur, L. (2009). From performativity to professionalism: Lecturers' responses to student feedback. Teaching in Higher Education, 14(4), 441-454. https://doi.org/10.1080/13562510903050228

- Ball, S.J. (2003). The teacher's soul and the terrors of performativity, Journal of Education Policy, 18(2), 215-228, DOI: $10.1080 / 0268093022000043065$

- Bennett, R., Uink, B. and Van den Berg, C. (2020). Educating Rita at the cultural interface: exploring intersections between race and gender in the experiences of Australian Aboriginal women at university. Diaspora, Indigenous, and Minority Education. pp. 1-15

- Biesta, G. J. J. (2010). Good Education in an Age of Measurement: Ethics, Politics, Democracy. Taylor \& Francis Group. http://ebookcentral.proquest.com/lib/deakin/detail.action?doclD=4186085

- Bissonette, D. (2017). The promise and perils of asynchronous learning: How faculty, students, and administrators can collaboratively increase retention and satisfaction in the online classroom, Journal of Pedagogic Development, 7(3), 13- 
23.

- Boud, D., \& Molloy, E. (2013). Rethinking models of feedback for learning: the challenge of design. Assessment \& Evaluation in Higher Education, 38(6), 698-712. https://doi.org/10.1080/02602938.2012.691462

- Bullen, J., Roberts, L., Davis, C., Hill, B., Lipscombe, T., and Cox, D. (2021). Comfort with discomfort: Exploring Wadjella educators' engagement with Indigenous students. National Centre for Student Equity in Higher Education (NCSEHE). Retrieved from https://www.ncsehe.edu.au/publications/wadjella-educators-engagement-indigenousstudents/

- Canty, A.J., Chase, J., Hingston, M., Greenwood, M., Mainsbridge, C.P, and Skalicky, J. (2020). Addressing student attrition within higher education online programs through a collaborativecommunity of practice', Journal of Applied Learning \& Teaching. 3(Sp.Is.), 1-12. DOI: 10.37074/jalt.2020.3.s1.3.

- Cardak, B., Brett, M., Bowden, M., Vecci, J., Barry, P., Bahtsevanoglou, J., \& McAllister, R. (2017). Regional Student Participation and Migration: Analysis of factors influencing regional student participation and internal migration in Australian higher education. Retrieved from https://www.ncsehe.edu.au/wp-content/uploads/2017/02/Regional-StudentParticipation-and-Migration-20170227-Final.pdf

- Carless, D. (2013). "Trust and Its Role in Facilitating Dialogic Feedback.” In Feedback in Higher and Professional Education, edited by D. Boud and E. Molloy, 91-102. New York, NY: Routledge.

- Cavanagh, A., Chen, X., Bathgate, M., Frederick, J., Hanauer, D., and Graham, M. J. (2018). CBE-Life Sciences Education. 17(1), 1-8.

- Chawinga, W. D., \& Andrew, Z. P. (2016). Increasing access to higher education through open and distance learning: Empirical findings from Mzuzu University, Malawi. International Review of Research in Open and Distributed Learning, 17(4). https://doi.org/10.19173/irrodl.v17i4.2409

- Chesters, J., \& Watson, L. (2014). Returns to education for those returning to education: Evidence from Australia. Studies in Higher Education, 39(9), 1634-1648. https://doi.org/10.1080/03075079.2013.801422

- Chickering, A., \& Gamson, Z. (1987). Seven principles of good practice in undergraduate education. AAHE Bulletin, 39, $3-7$.

- Choi, Byoung Kwon, Moon, Hyoung Koo \& Nae, Eun Young. (2014). Cognition- and Affect-Based Trust and FeedbackSeeking Behavior: The Roles of Value, Cost, and Goal Orientations, The Journal of Psychology, 148:5, 603-620, DOI: $10.1080 / 00223980.2013 .818928$

- Connell, R. (2013). The neoliberal cascade and education: An essay on the market agenda and its consequences. Critical Studies in Education, 54(2), 99-112. https://doi.org/10.1080/17508487.2013.776990

- Crawford, N. L. (2021). “On the radar”: Supporting students' mental wellbeing: mature-aged students in regional \& remote Australia. In https://www.ncsehe.edu.au/publications/nicole-crawford-equity-fellowship-mental-wellbeing$\underline{\text { mature-students-regional-remote-australia/ }}$

- Crawford, N. L. \& Johns, S. (2018). An Academic's Role? Supporting Student Wellbeing in Pre-university Enabling Programs, Journal of University Teaching \& Learning Practice, 15(3), 2018. Available at: https://ro.uow.edu.au/jutlp/vol15/iss3/2

- Crommelinck, M. and Anseel, F. (2013), Understanding and encouraging feedback-seeking behaviour: a literature 
review. Medical Education, 47: 232-241. https://doi-org.ezproxy-f.deakin.edu.au/10.1111/medu.12075

- Day, A., Nakata, V., Nakata, M., \& Martin, G. (2015). Indigenous students' persistence in higher education in Australia: Contextualising models of change from psychology to understand and aid students' practices at a cultural interface. Higher Education Research \& Development, 34(3), 501-512. https://doi.org/10.1080/07294360.2014.973379

- DESE. (2017a). Completion Rates of Higher Education Students- Cohort Analysis, 2005-2014. Retrieved from https://docs.education.gov.au/documents/completion-rates-higher-education-students-cohort-analysis-2005-2014.

- DESE. (2017b). Improving Retention, Completion and Success in Higher Education. Canberra: Australian Government. Retrieved from https://docs.education.gov.au/node/44121.

- DESE. (2019). Higher Education Statistics - Student Data. Canberra. Australia Government. Retrieved from https://www.education.gov.au/student-data

- Devlin, M., \& McKay, J. (2016). Teaching students using technology: Facilitating success for students from low socioeconomic status backgrounds in Australian universities. Australasian Journal of Educational Technology, 32(1), 92-106. https://doi.org/10.14742/ajet.2053

- Devlin, M., \& McKay, J. (2018). Teaching inclusively online in a massified university system. Widening Participation and Lifelong Learning, 20(1), 146-166. doi:https://doi.org/10.5456/WPLL.20.1.146

- Dijk, J. van. (2005). The deepening divide: inequality in the information society. Sage Publications.

- Dimaggio, P.J., \& Hargittai, E. (2001). From the 'digital divide' to 'digital inequality'.

- Dodo-Balu, A. (2018). Fairness and inclusion: Online learning as an enabler of Australian higher education policies aimed at student equity and social justice. International studies in widening participation, 5(2), 26-39. https://novaojs.newcastle.edu.au/ceehe/index.php/iswp/article/view/103/pdf 30

- Dobransky, K., \& Hargittai, E. (2016). Unrealized potential: Exploring the digital disability divide. Poetics, 58, 18-28. https://doi.org/10.1016/j.poetic.2016.08.003

- Dreamson, N., Thomas, G., Lee Hong, A. \& Kim, S. (2016) Culturally Inclusive Learning for Indigenous Students in a Learning Management System (LMS). Report submitted to the National Centre for Student Equity in Higher Education (NCSEHE), Curtin University: Perth.

- Dron, J., Seidel, C., \& Litten, G. (2004). Transactional distance in a blended learning environment. ALT-J: Research in Learning Technology, 163-174.

- Dyment, J., Stone C., \& Milthorpe, N. (2020). Beyond busy work: rethinking the measurement of online student engagement. Higher Education Research \& Development, 39(7), 1440-1453, DOI: 10.1080/07294360.2020.1732879

- Ergeneli, A., Arı, G. S., Metin, S. (2007). Psychological empowerment and its relationship to trust in immediate managers. Journal of Business Research. 60(1), 41-49. https://doi.org/10.1016/j.jbusres.2006.09.012

- Flodén, J. (2017). The impact of student feedback on teaching in higher education. Assessment \& Evaluation in Higher Education, 42(7), 1054-1068. https://doi.org/10.1080/02602938.2016.1224997

- Grayling, A.C. (2015). What Makes a Good Teacher? The Chronicle of Higher Education. https://www.chronicle.com/article/what-makes-a-good-teacher-234422/

- Ghosh, Amit K., Whipple, Thomas W. \& Bryan, Glenn A. (2001) Student Trust and its Antecedents in Higher Education, 
The Journal of Higher Education, 72:3, 322-340, DOI: 10.1080/00221546.2001.11777097

- Greenland, S. J., \& Moore, C. (2014). Patterns of student enrolment and attrition in Australian open access online education: A preliminary case study. Open Praxis, 6(1), 45-54. https://doi.org/10.5944/openpraxis.6.1.95

- Gould, J., \& Day, P. (2013). Hearing you loud and clear: Student perspectives of audio feedback in higher education. Assessment \& Evaluation in Higher Education, 38(5), 554-566. https://doi.org/10.1080/02602938.2012.660131

- Gunkel, D. J. (2003). Second Thoughts: Toward a Critique of the Digital Divide. New Media \& Society, 5(4), 499-522. https://doi.org/10.1177/146144480354003

- Gwebu, K., Wang, J., and Troutt, M. (2007). A Conceptual Framework for Understanding Trust Building and Maintenance in Virtual Organizations. Journal of Information Technology Theory and Application (JITTA). 9(1). 43-63.

- Hargittai, E., \& Hsieh, Y. P. (2013). Digital Inequality. The Oxford Handbook of Internet Studies. https://doi.org/10.1093/oxfordhb/9780199589074.013.0007

- Halsey, J. (2018). Independent review into regional, rural and remote education. Final report. Commonwealth of Australia. https://docs.education.gov.au/node/50281

- Hewson, E. R. F. (2018). Students' emotional engagement, motivation and behaviour over the life of an online course: Reflections of two market research case studies. Journal of Interactive Media in Education, 1(10), 1-13. https://doi.org/10.5334/jime.472

- Hill, C., \& Lawton, W. (2018). Universities, the digital divide and global inequality. Journal of Higher Education Policy and Management, 40(6), 598-610. https://doi.org/10.1080/1360080X.2018.1531211

- Hitch, D., Mahoney, P., \& Macfarlane, S., (2017). Professional development for sessional staff in higher education: a review of current evidence. Higher Education Research \& Development, pp. 285-300, DOI: $10.1080 / 07294360.2017 .1360844$

- Holloway, J. (2020). Teacher accountability, datafication, and evaluation: A case for reimagining schooling. Education Policy Analysis Archives, 28(56). https://doi.org/10.14507/epaa.28.5026

- Holloway, J., \& Brass, J. (2017). Making accountable teachers: The terrors and pleasures of performativity. https://doi.org/10.1080/02680939.2017.1372636

- Huang, J.-T. (2012), Be Proactive as Empowered. Journal of Applied Social Psychology. 42: E103-E127. https://doi.org/10.1111/j.1559-1816.2012.01019.x

- Hwang A., Francesco A.M. (2010). The influence of individualism-collectivism and power distance on use of feedback channels and consequences for learning. Academy of Management Learning \& Education. 9(2), 243-57. https://doi.org/10.5465/amle.9.2.zqr243

- Ilgaz, H., \& Gülbahar, Y. (2015). A Snapshot of Online Learners: e-Readiness, e-Satisfaction and Expectations. International Review of Research in Open and Distributed Learning, 16(2), 171-187. Retrieved from http://www.irrodl.org/index.php/irrodl/article/view/2117/3277

- Jarvenpaa, S., Knoll, K., \& Leidner, D. (1998). Is Anybody out There? Antecedents of Trust in Global Virtual Teams. Journal of Management Information Systems, 14(4), 29-64. Retrieved March 18, 2021, from http://www.jstor.org/stable/40398291

- Jones, A. \& Bennett, B. (2017) Reaching beyond an online/offline divide: invoking the rhizome in higher education 
course design, Technology, Pedagogy and Education, 26:2, 193-210, DOI: 10.1080/1475939X.2016.1201527

- Jones, G. R. and George, J. M. (1998). The Academy of Management Review, Vol. 23, No. 3. pp. 531-546 https://www.jstor.org/stable/259293

- Joughin, G., Boud, D., Dawson, P. \& Tai, J. (2020). What can higher education learn from feedback seeking behaviour in organisations? Implications for feedback literacy. Assessment \& Evaluation in Higher Education, 46:1, 80-91, DOI: $10.1080 / 02602938.2020 .1733491$

- Keddie, A., Black, R., \& Charles, C. (2020). Conceptions of performativity, responsibility and care within a University excellence program. Australian Educational Researcher, 47, 95-111. https://doi.org/10.1007/s13384-019-00322-6

- Kelly, P., Coates, H., \& Naylor, R. (2016). Leading Online Education from Participation to Success. Educational Studies Moscow, 3(2016), 34-58.

- Kent, M. (2015). Access and Barriers to Online Education for People with Disabilities. Retrieved from https://www.ncsehe.edu.au/wp-content/uploads/2016/05/Access-and-Barriers-to-Online-Education-for-People-withDisabilities.pdf.

- Knightley, W.M. (2007). Adult learners online: students' experiences of online learning. Australian Journal of Adult Learning, 47(2), 264-288.

- Kumaran, K. S. R., Yin, Y., \& Bailey, B. P. (2021). Plan Early, Revise More: Effects of Goal Setting and Perceived Role of the Feedback Provider on Feedback Seeking Behavior. Proceedings of the ACM on Human-Computer Interaction, 5(CSCW1), 24:1-24:22. https://doi.org/10.1145/3449098

- Lambrinidis, G. (2014). Supporting online, non-traditional students through the introduction of effective e-learning tools in a pre-university tertiary enabling programme. Journal of Higher Education Policy and Management, 36(3), 257-267.

- Leenknecht, M., Hompus, P., \& van der Schaaf, M. (2019). Feedback seeking behaviour in higher education: the association with students' goal orientation and deep learning approach, Assessment \& Evaluation in Higher Education, 44:7, 1069-1078, DOI: 10.1080/02602938.2019.1571161

- Lewis, M. D. (2017). Demographics of online students. In S. L. Danver (Ed.), The SAGE Encyclopedia of Online Education. Walden University USA: SAGE.

- Macklin, J. (2020). Future Skills for Victoria, Driving collaboration and innovation in post-secondary education and training, Victorian Government, Melbourne.

- Mallman, M., \& Lee, H. (2016). Stigmatised learners: Mature age students negotiating university culture. British Journal of Sociology, 37(5), 684-701. https://doi.org/10.1080/01425692.2014.973017

- Martin, A. J. (2006). A Motivational Psychology for the Education of Indigenous Australian Students. The Australian Journal of Indigenous Education, 35, 30-43. https://doi.org/10.1017/S1326011100004142

- Martin, L. (2020). Foundations for good practice: The student experience of online learning in Australian higher education during the COVID-19 pandemic. Canberra: Australian Government Tertiary Education Quality and Standards Agency (TESQA).

- Mayer, R.C., Davis, J.H., \& Schoorman, F.D. (1995). An integrative model of organizational trust. Academy of Management Review, 20, 709-734. doi: 10.2307/258792

- McAllister. D.J. (1995). Affect- and cognition-based trust as foundations for interpersonal cooperation in organizations. 
Academy of Management Journal, 38, 24-59. doi: 10.2307/256727

- Molloy, E. and Bearman, M. (2018). Embracing the tension between vulnerability and credibility: 'intellectual candour' in health professions education. Med Educ, 53: 32-41. https://doi.org/10.1111/medu.13649

- Moore, C., \& Greenland, S. J. (2017). Employment-driven online student attrition and the assessment policy divide: An Australian open-access higher education perspective. Journal of Open, Flexible and Distance Learning, 21(1), 52-62.

- Mordal Moen, K., Westlie, K., Gerdin, G., Smith, W., Linnér, S., Philpot, R., Schenker, K., \& Larsson, K. (2020) Caring teaching and the complexity of building good relationships as pedagogies for social justice in health and physical education, Sport, Education and Society, 25:9, 1015-1028, DOI: 10.1080/13573322.2019.1683535

- Mukandi, B., \& Bond, C. (2019). 'Good in the Hood' or 'Burn It Down'? Reconciling Black Presence in the Academy. Journal of Intercultural Studies, 40(2), 254-268. https://doi.org/10.1080/07256868.2019.1577232

- Nakata, M., Nakata, V., \& Chin, M. (2004). Approaches to the Academic Preparation and Support of Australian Indigenous Students for Tertiary Studies. https://opus.lib.uts.edu.au/handle/10453/12881

- Noddings, N. (2013). Caring: A relational approach to ethics and moral education. Univ of California Press.

- Park, J. and Choi, H. (2009) 'Factors influencing adult learners' decision to dropout or persist in online learning', Educational Technology and Society, 12: 4, 207-217.

- Payne A.L. (2021a). A resource for e-moderators on fostering participatory engagement within discussion boards for online students in higher education. A practice report. Student Success, 12(1), 93-101. https://doi.org/10.5204/ssj.1865

- Payne, A.L. (2021b). 'A lot of us can relate to struggling to keep on top of everything.' This is what mature-age students need from online higher education. The Conversation. Available at: https://theconversation.com/a-lot-of-us-can-relate-tostruggling-to-keep-on-top-of-everything-this-is-what-mature-age-students-need-from-online-higher-education-155201

- Payne, A. L. (2021c). Technology-enhanced feedback in higher education: Source-recipient relationships in a new dialogic paradigm. EdArXiv 1-16. https://doi.org/10.35542/osf.io/9ehgb

- Pocock, B., Skinner, N., \& Ichii, R. (2009). Work, life and workplace flexibility: The Australian work and life index (AWALI) 2009. Adelaide: University of South Australia. Retrieved from https://ap01a.alma.exlibrisgroup.com/view/delivery/61USOUTHAUS INST/12143306900001831

- Pollard, L. (2018). Remote student university success: An analysis of policy and practice. Perth, Western Australia. Retrieved from https://www.ncsehe.edu.au/publications/remote-student-university-success-analysis-policy-practice/.

- Ragusa, A. T., \& Crampton, A. (2018). Sense of connection, identity and academic success in distance education: Sociologically exploring online learning environments. Rural Society, 27(2), 125-142. doi:10.1080/10371656.2018.1472914

- Raufelder, D., Nitsche, L., Breitmeyer, S., Keßler, S., Herrmann, E., Regner ,N. (2016). Students' perception of "good" and "bad" teachers-Results of a qualitative thematic analysis with German adolescents. International Journal of Educational Research, 75, 31-44.

- Read, B., \& Leathwood, C. (2020). Casualised academic staff and the lecturer-student relationship: Shame, (Im)permanence and (II)legitimacy. British Journal of Sociology of Education, 41(4), 539-554. https://doi.org/10.1080/01425692.2020.1748570 Redmond, P., Heffernan, A., Abawi, L., Brown, A., \& Henderson, R. (2018). An online engagement framework for higher 
education. Online Learning, 22(1), 183-204. doi:10.24059/olj.v22i1.1175

- Resop Reilly, J., Gallagher-Lepak, S., \& Killion, C. (2012). "Me and my computer": emotional factors in online learning. Nursing Education Perspectives, 33(2), 100-105. Retrieved from https://www.ncbi.nlm.nih.gov/pubmed/22616408 Rourke, L., Anderson, T., Garrison, D. R., \& Archer, W. (2001). Assessing social presence in asynchronous, text-based computer conferencing. Journal of Distance Education, 14(3), 51-70

- Salmon, G. (2014). Learning Innovation: A Framework for Transformation. European Journal of Open, Distance and eLearning, 17(2), 219-235. doi:https://doi.org/10.2478/eurodl-2014-0031

- Schmidt, T. (2019). Teacher as person: the need for an alternative conceptualisation of the 'good' teacher in Australia's Vocational Education And Training sector, Journal of Vocational Education \& Training, 73:1, 148-165, DOI: $10.1080 / 13636820.2019 .1698646$

Shield, R.W. (2009). Identifying and Understanding Indigenous Cultural and Spiritual Strengths in the Higher Education Experiences of Indigenous Women. Wicazo Sa Review 24(1), 47-63. doi:10.1353/wic.0.0022.

- Singh, M. (2001). Reinserting the 'public good' into higher education transformation. Kagisano Higher Education Discussion Series, 1, 8-18.

- Signor, L., \& Moore, C. (2014). Open access in higher education: Strategies for engaging diverse student cohorts. Open Praxis, 6(3), 305-313. http://dx.doi.org/10.5944/openpraxis.6.3.132

- Simper, N., Maynard, N. \& Mårtensson, K. (2021): Informal academic networks and the value of significant social interactions in supporting quality assessment practices, Higher Education Research \& Development, DOI: $10.1080 / 07294360.2021 .1896481$

- Smith, J. (2017). Target-setting, early-career academic identities and the measurement culture of UK higher education, Higher Education Research \& Development, 36(3), 597-611, DOI: 10.1080/07294360.2017.1288708

- Stern, M. J., Adams, A. E., \& Elsasser, S. (2009). Digital Inequality and Place: The Effects of Technological Diffusion on Internet Proficiency and Usage across Rural, Suburban, and Urban Counties*. Sociological Inquiry, 79(4), 391-417. https://doi.org/10.1111/j.1475-682X.2009.00302.x

- Stone, C. (2017). Opportunity through online learning: Improving student access, participation and success in higher education. Equity Fellowship Final Report. The National Centre for Student Equity in Higher Education, Curtin University, Perth, Australia. Retrieved from https://www.ncsehe.edu.au/publications/opportunity-online-learning-improving-student-access-participation-successhigher-education/

- Stone, C. (2019). Online learning in Australian higher education: Opportunities, challenges and transformations. Student Success, 10(2), 1-11. https://doi.org/10.5204/ssj.v10i2.1299

- Stone, C. \& Davis, M. (2020). Stark inequality of online access for rural-remote students. EduResearch Matters, Australian Association for Research in Education, June 15. https://www.aare.edu.au/blog/?p=5524

- Stone, C. \& O'Shea, S. (2012). Transformations and self-discovery: Women returning to study. Champaign, IL: Common Ground Publishing. https://doi.org/10.18848/978-1-61229-031-7/CGP

- Stone, C., \& O'Shea, S. (2013). Time, money, leisure and guilt - the gendered challenges of higher education for mature-age students. Australian Journal of Adult Learning, 53(1), 95-116. 
- Stone, C. \& O'Shea, S. (2019a). Older, online and first: Recommendations for retention and success. Australasian Journal of Educational Technology, 35(1), 57-69. https://doi.org/10.14742/ajet.3913

- Stone, C., \& O'Shea, S. (2019b). My children ... think it's cool that Mum is a uni student: Women with caring responsibilities studying online. Australasian Journal of Educational Technology, 35(6), 97-110. https://doi.org/10.14742/ajet.5504

- Stone, C., \& Springer, M. (2019). Interactivity, connectedness and 'teacher-presence': Engaging and retaining students online. Australian Journal of Adult Learning, 59(2), 146-169.

- Stone, C., Freeman, E., Dyment, J., Muir, T., \& Milthorpe, N. (2019). Equal or equitable: The role of flexibility within online education. Australian and International Journal of Rural Education, 29(2), 79-92. Retrieved from https://journal.spera.asn.au/index.php/AlJRE/issue/view/32

- Stone, C., O'Shea, S., May, J., Delahunty, J., \& Partington, Z. (2016). Opportunity through online learning: experiences of first-in-family students in online open-entry higher education. Australian Journal of Adult Learning, 56(2), 146-169. https://www.ajal.net.au/opportunity-through-online-learning-experiences-of-first-in-family-students-in-online-open-entryhigher-education/

- Sybing, R. (2019). Making Connections: Student-Teacher Rapport in Higher Education Classrooms: Student-teacher rapport in higher education classrooms. Journal of the Scholarship of Teaching and Learning, 19(5). https://doi.org/10.14434/josotl.v19i5.26578

- Te Riele, K. (2004). The human face of 'effective schooling' for marginalised young women. Paper prepared for the Learning from the Margins Conference, July 2004, Melbourne. Published on-line by the Quality Learning Research Priority Area, Deakin University, Geelong. http://www.deakin.edu.au/education/quality learning

- The Social Research Centre. (2021). 2020 SES National Report. Canberra: The Social Research Centre. Retrieved from https://www.qilt.edu.au/qilt-surveys/student-experience

Thomas, J., Barraket, J., Wilson, C., Ewing, S., MacDonald, T., Tucker, J., Rennie, E., (2017). Measuring Australia's Digital Divide: The Australian Digital Inclusion Index 2017, RMIT University, Melbourne, for Telstra. DOI: www.dx.doi.org/10.4225/50/596473db69505

Thunig, A. \& Pearson, L. (2019). New media, ancient culture: the power and potential of social media in Indigenous education. Abstract from AARE 2019 Conference, Brisbane, Australia. https://www.aare.edu.au/publications/aareconference-papers/show/12549/new-media-ancient-culture-the-power-and-potential-of-social-media-in-indigenouseducation

- Uink, B., Bennett, R. \& van den Berg, C. (2021) Factors that enable Australian Aboriginal women's persistence at university: a strengths-based approach, Higher Education Research \& Development, 40:1, 178-193, DOI: $10.1080 / 07294360.2020 .1852185$

- Universities Australia (2020). Snapshot 2020. Retrieved from https://www.universitiesaustralia.edu.au/publication/snapshot-2020/ Vaughan, N., \& Garrison, R. (2006). A blended faculty community of inquiry: Linking leadership, course redesign, and evaluation. Canadian Journal of University Continuing Education, 32(2), 67-92.

- Vincenzes, K. A., \& Drew, M. (2017). Facilitating interactive relationships with students online. Distance Learning, 14(4), 
13-22.

- Wilkins, R., \& Lass I. (2018). The Household, Income and Labour Dynamics in Australia Survey: Selected Findings from Waves 1 to 16. Melbourne Institute: Applied Economic \& Social Research, University of Melbourne. Retrieved from https://melbourneinstitute.unimelb.edu.au/_data/assets/pdf_file/0005/2839919/2018-HILDA-SR-for-web.pdf

- Xu, Y., \& Carless, D. (2017) 'Only true friends could be cruelly honest': cognitive scaffolding and social-affective support in teacher feedback literacy, Assessment \& Evaluation in Higher Education, 42:7, 1082-1094, DOI:

10.1080/02602938.2016.1226759

Zhou, J., Dawson, P., Tai, JHM \& Bearman, M. (2021) How conceptualising respect can inform feedback pedagogies, Assessment \& Evaluation in Higher Education, 46:1, 68-79, DOI: 10.1080/02602938.2020.1733490 